\title{
Associations between serotype and susceptibility to antibiotics of Neisseria gonorrhoeae
}

\author{
N WOODFORD, K M BINDAYNA, C S F EASMON, C A ISON \\ From the Department of Medical Microbiology, Wright-Fleming Institute, St Mary's Hospital Medical School, \\ London
}

SUMMARY A serological classification scheme for Neisseria gonorrhoeae was used to investigate the epidemiological associations between gonococcal serotype and other bacterial and host characters. Six hundred and fifty clinical isolates of non-penicillinase producing $N$ gonorrhoeae from the Praed Street Clinic, St Mary's Hospital, were included in this study.

The strains collected represented 41 serovars, although $485(75 \%)$ of the 650 strains belonged to five serovars. Strains of serovar IA-1/2 were commonly isolated from the cervix and tended to be sensitive to penicillin and moderately resistant to erythromycin. Strains of serovar IB-1 showed bimodal patterns of susceptibility to both penicillin and erythromycin and were obtained equally from all anatomical sites. Strains of serovar IB-2 were isolated more often from the rectum and were associated with homosexually acquired infections, whereas those of serovar IB-3 were sensitive to erythromycin and were rarely isolated from the rectum. Strains of IB-5/7 were more resistant to penicillin and erythromycin than strains of other serovars.

The serological classification of $N$ gonorrhoeae is thus a powerful tool that may be used to study biological characteristics of the gonococcus, such as susceptibility to antimicrobials and site tropism.

Chromosomal resistance to antibiotics in Neisseria gonorrhoeae has been a continual problem since the introduction of sulphonamides as treatment in the 1930s. Resistance to these agents emerged rapidly, and penicillin was adopted as the treatment of choice. Decreased susceptibility to penicillin was first described by Reyn,' but was easily overcome by increased dosage. Treatment failure because of chromosomally mediated resistant $N$ gonorrhoeae did not appear in the United States of America until 1983, ${ }^{2}$ although such strains had been identified previously in the Far East. ${ }^{3}$ These strains are resistant to $1 \mathrm{mg} / \mathrm{l}$ or more penicillin as a result of the cumulative effect of several distinct chromosomal mutations. ${ }^{4}$

Strains of $N$ gonorrhoeae with similar levels of resistance have been reported from throughout the United States of America ${ }^{5}$ and the United Kingdom. ${ }^{67}$ The epidemiology of gonococcal resistance to antibiotics has been difficult to study because of the lack of a typing scheme with sufficient discrimination.

Address for reprints: Dr C A Ison, Department of Medical Microbiology, Wright-Fleming Institute, St Mary’s Hospital Medical School, London W2 1PG.

Accepted for publication 29 July 1988
The development of a serological classification scheme using monoclonal antibodies raised to epitopes on the gonococcal outer membrane protein, $\mathrm{PI}^{8}{ }^{8}$ has enabled detailed epidemiological studies to be performed. ${ }^{910}$

We have reported previously the epidemiological associations between the auxotype, serogroup, and susceptibility to antimicrobials of non-penicillinase producing $N$ gonorrhoeae (non-PPNG) isolated at the Praed Street Clinic, St Mary's Hospital, London. ${ }^{7}$ We have used the serotyping scheme to extend these studies and report here the associations found between gonococcal serotype, susceptibility to antimicrobials, and site of infection and the sexual preference of the patient.

\section{Patients, materials, and methods}

\section{BACTERIA}

We used 650 non-PPNG strains isolated from patients attending the Praed Street Clinic for sexually transmitted diseases. We collected about 20 strains a month from November 1984 to August 1987. Of these, 334 were isolated from men ( 275 from the urethra, 59 from the rectum) and 316 from women (all from the cervix). 
Male patients were designated homosexual if they had had any sexual contact with other men (111 patients).

\section{ISOLATION AND IDENTIFICATION}

We isolated all strains on GC agar base (BBL) supplemented with $1 \%$ IsoVitaleX (BBL), vancomycin $(3 \mathrm{mg} / \mathrm{l})$, colistin $(1000 \mathrm{IU} / \mathrm{l})$, trimethoprim $(5 \mathrm{mg} / \mathrm{l})$, and amphotericin $(1.5 \mathrm{mg} / \mathrm{l})$. We incubated cultures for 48 hours at $36^{\circ} \mathrm{C}$ in $6 \%$ carbon dioxide. Isolates were identified as $N$ gonorrhoeae if they were oxidase positive Gram negative cocci, produced acid from glucose but not from maltose or sucrose, and failed to produce $\beta$ galactosidase. The inability to produce penicillinase was confirmed using the chromogenic cephalosporin, Nitrocefin (Oxoid). We made all further subcultures on GC agar base (Difco) with $1 \%$ IsoVitaleX and no antibiotics. We suspended the strains in $15 \%$ glycerol broth and stored them in vapour phase liquid nitrogen $\left(-135^{\circ} \mathrm{C}\right)$ until they were required.

\section{SUSCEPTIBILITY TESTING}

We assessed the minimum inhibitory concentration (MIC) of 642 strains using the agar dilution technique described previously. ${ }^{7}$ The medium used was diagnostic sensitivity test agar (DST; Oxoid) supplemented with $1 \%$ IsoVitaleX and $5 \%$ lysed horse blood (Tissue Culture Services). The antibiotics we tested were penicillin $(0.008-4 \mathrm{mg} / \mathrm{l})$, cefuroxime $(0.008-1 \mathrm{mg} / \mathrm{l})$, tetracycline $(0.03-8 \mathrm{mg} / \mathrm{l})$, erythromycin $(0.015-8 \mathrm{mg} /$ $1)$, and spectinomycin (8-64 $\mathrm{mg} / \mathrm{l})$. We used an inoculum of $10^{5}$ colony forming units (cfu) and read the end point of complete inhibition (the minimum inhibitory concentration (MIC) of each antibiotic) after incubation for 48 hours at $36^{\circ} \mathrm{C}$ in $6 \%$ carbon dioxide.

\section{SEROTYPING}

We used a panel of twelve monoclonal antibodies raised to epitopes on the outer membrane protein, PI, supplied by Syva, Palo Alto, USA, to classify strains of $N$ gonorrhoeae serologically. This panel consisted of six antibodies specific for PIA and six specific for PIB mixed with Staphylococcus aureus that contained protein $\mathrm{A}$. We used the antibodies in a coagglutination system as described by Knapp et al. ${ }^{8}$

We prepared bacterial suspensions from an overnight growth on GC agar base (Difco) with 1\% IsoVitaleX. We subcultured all strains at least twice after recovering them from the culture collection and before testing them. Organisms were suspended in phosphate buffered saline $(0 \cdot 15 \mathrm{~mol} / \mathrm{l})$, boiled for ten minutes, and allowed to cool. We mixed equal amounts of bacterial suspension and antibody on a glass slide by rotating it for two minutes exactly. The serovar was assigned using the nomenclature of Knapp et al. ${ }^{8}$

We used the Phadebact GC monoclonal test (Pharmacia) to group strains that did not react with any of the serotyping antibodies.

\section{AUXOTYPING}

Using the defined media of Copley and Egglestone, we investigated nutritional requirements." We tested strains for their requirement for proline ( $\left.\mathrm{pro}^{-}\right)$, argin-

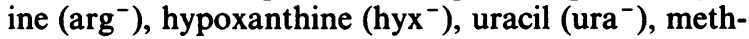
ionine $\left(\mathrm{met}^{-}\right)$, and histidine (his $\left.{ }^{-}\right)$. In addition, we tested strains requiring arginine for their ability to utilise ornithine $\left(\mathrm{orn}^{-}\right)$as an alternative substrate.

\section{STATISTICAL ANALYSIS}

We analysed the data using the Statistical Package for Social Sciences (SPSS). Differences in the susceptibility to antibiotics of the predominant serovars were assessed using the Mann-Whitney test for significance of differences between median MICs. The $\chi^{2}$ test was used to investigate the association between the distribution of serovars and either the site of isolation or the sexual preference of the patient.

\section{Results}

In this population we identified 41 serovars, of which 16 were IA specific and 25 were IB specific. Thirteen strains did not belong to a recognised serovar, and their pattern of agglutination (with antibodies $3 \mathrm{C} 8$, $1 F 5,2 \mathrm{G} 2$, and $2 \mathrm{H} 1$ ) was subsequently designated serovar IB-31. A further 12 strains did not react with any of the antibodies, although one belonged to serogroup IA and 11 to serogroup IB when tested with the Phadebact GC monoclonal test (Pharmacia).

We found 20 auxotypes and 117 auxotype/serovar classes. Table 1 shows the auxotype/serovar classes represented. Fifty four auxotype/serovar classes accounted for $539(83 \%)$ of the 650 strains (data not shown). In this study we grouped together serovars IA-1 and IA-2 as has been suggested by Knapp et al. ${ }^{9}$ Serovars IB-5 and IB-7, which differed only in their reaction with a single antibody, had similar antibiotic susceptibilities and site associations and were consequently grouped together to give sufficient numbers for further statistical analysis. Five serovars, IA-1/2, IB-1, IB-2, IB-3, and IB-5/7, encompassed 485/650 $(75 \%)$ strains, and each individual serovar represented more than $5 \%$ of the total population.

Figure 1 shows the distribution of susceptibility to penicillin for the five main serovars compared with that of the total population. The total population showed a bimodal distribution that was echoed by serovar IB-1 and, to a lesser extent, by serovars IB-2 and IB-3. In comparison, however, strains of serovar 
Table 1 Auxotype/serovar classes found in 650 clinical isolates of non-PPNG strains

\begin{tabular}{|c|c|c|c|c|c|c|c|c|}
\hline \multirow[b]{2}{*}{ Serovar } & \multirow{2}{*}{$\begin{array}{l}\text { No }(\%) \text { in } \\
\text { population } \\
(n=650)\end{array}$} & \multicolumn{7}{|c|}{ No belonging to auxotype } \\
\hline & & Pro & $\mathrm{Pro}^{-}$ & $A H U^{-}$ & $\mathrm{Arg}^{-}$ & $P A^{-}$ & $P A U^{-}$ & Others \\
\hline $\begin{array}{l}\text { IA-1/2 } \\
\text { IB-1 } \\
\text { IB-3 } \\
\text { IB-2 } \\
\text { IB-5/7 } \\
\text { IB-8 } \\
\text { IB-31 } \\
\text { IB-16 } \\
\text { IB-6 } \\
\text { IA-6 } \\
\text { IA-4 } \\
\text { IA-10 } \\
\text { IB-4 } \\
\text { IB-26 } \\
\text { Others }\end{array}$ & $\begin{array}{c}147(22 \cdot 6) \\
115(17 \cdot 7) \\
107(16 \cdot 5) \\
83(12 \cdot 8) \\
33(5 \cdot 1) \\
14(2 \cdot 2) \\
13(2 \cdot 0) \\
12(1 \cdot 8) \\
11(1 \cdot 7) \\
11(1 \cdot 7) \\
10(1 \cdot 5) \\
8(1 \cdot 2) \\
8(1 \cdot 2) \\
7(1 \cdot 1) \\
71(10.9)\end{array}$ & $\begin{array}{r}23 \\
43 \\
73 \\
28 \\
21 \\
9 \\
6 \\
2 \\
9 \\
6 \\
7 \\
3 \\
6 \\
2 \\
35\end{array}$ & $\begin{array}{r}4 \\
41 \\
14 \\
16 \\
9 \\
1 \\
2 \\
2 \\
1 \\
4 \\
3 \\
1 \\
1 \\
2 \\
18\end{array}$ & $\begin{array}{l}88 \\
1 \\
0 \\
1 \\
0 \\
0 \\
0 \\
0 \\
0 \\
1 \\
0 \\
2 \\
0 \\
0 \\
3\end{array}$ & $\begin{array}{r}7 \\
13 \\
18 \\
4 \\
1 \\
0 \\
4 \\
1 \\
0 \\
0 \\
0 \\
2 \\
1 \\
0 \\
9\end{array}$ & $\begin{array}{r}1 \\
10 \\
1 \\
5 \\
1 \\
0 \\
1 \\
0 \\
0 \\
0 \\
0 \\
0 \\
0 \\
2 \\
0\end{array}$ & $\begin{array}{r}1 \\
0 \\
0 \\
27 \\
0 \\
0 \\
0 \\
7 \\
0 \\
0 \\
0 \\
0 \\
0 \\
0 \\
3\end{array}$ & $\begin{array}{r}23 \\
7 \\
1 \\
2 \\
1 \\
4 \\
0 \\
0 \\
1 \\
0 \\
0 \\
0 \\
0 \\
1 \\
3\end{array}$ \\
\hline
\end{tabular}

Proto $=$ prototrophic; $\mathrm{Pro}^{-}=$require proline; $\mathrm{AHU}^{-}=$require arginine, hypoxanthine, and uracil; $\mathrm{Arg}^{-}=$require arginine; $\mathrm{PA}^{-}=$require proline and arginine; $\mathrm{PAU}^{-}=$require proline, arginine, and uracil, but will not use ornithine.

IA-1/2 showed a significantly $(p=<0.001)$ higher susceptibility and those of serovar IB-5/7 a significantly $(\mathrm{p}=<0.02)$ lower susceptibility than other strains. Thus most $(111 / 147(75.5 \%))$ strains of serovar IA-1/2 were sensitive to penicillin (MIC $\leq 0.06 \mathrm{mg} / \mathrm{l})$ whereas most $(23 / 33(69.7 \%))$ strains of serovar IB-5/7 tended to be more resistant (MIC $\geq 0.5 \mathrm{mg} / \mathrm{l})$.

We found no significant differences between the degrees of median susceptibility to erythromycin for serovars IA-1/2, IB-1, IB-2 and the total population (fig 2). Strains of serovar IB-1, however, showed a distinct bimodal distribution not seen in serovars IA1/2 or IB-2. In contrast, strains of serovar IB-3 showed significantly $(p=<0.01)$ higher susceptibility and those of IB-5/7 significantly ( $p=<0.01)$ higher resistance to erythromycin.

Similar differences in susceptibility to both cefuroxime and tetracycline were found (data not shown). Strains of serovar IB-1 showed bimodal distributions for both antibiotics, whereas strains of serovar IA-1/2 were sensitive and those of serovar IB-5/7 more resistant. The degree of susceptibility to spectinomycin fell within a narrow range (MIC 8-64 mg/l) for the whole population, but there were two serovar clusters that differed significantly. More strains of serovars IA-1/2, IB-1, and IB-3 were sensitive than strains of serovars IB-2 and IB-5/7 (p<0.01).

Table 2 shows that the serovars of rectal strains from men differed significantly $(p<0.001)$ from those of urethral strains from men and of cervical strains. Similar percentages of strains of serovar IB-1 were obtained from all three sites, but significantly $(p<0.001)$ more rectal $(18 / 59,31 \%)$ than urethral
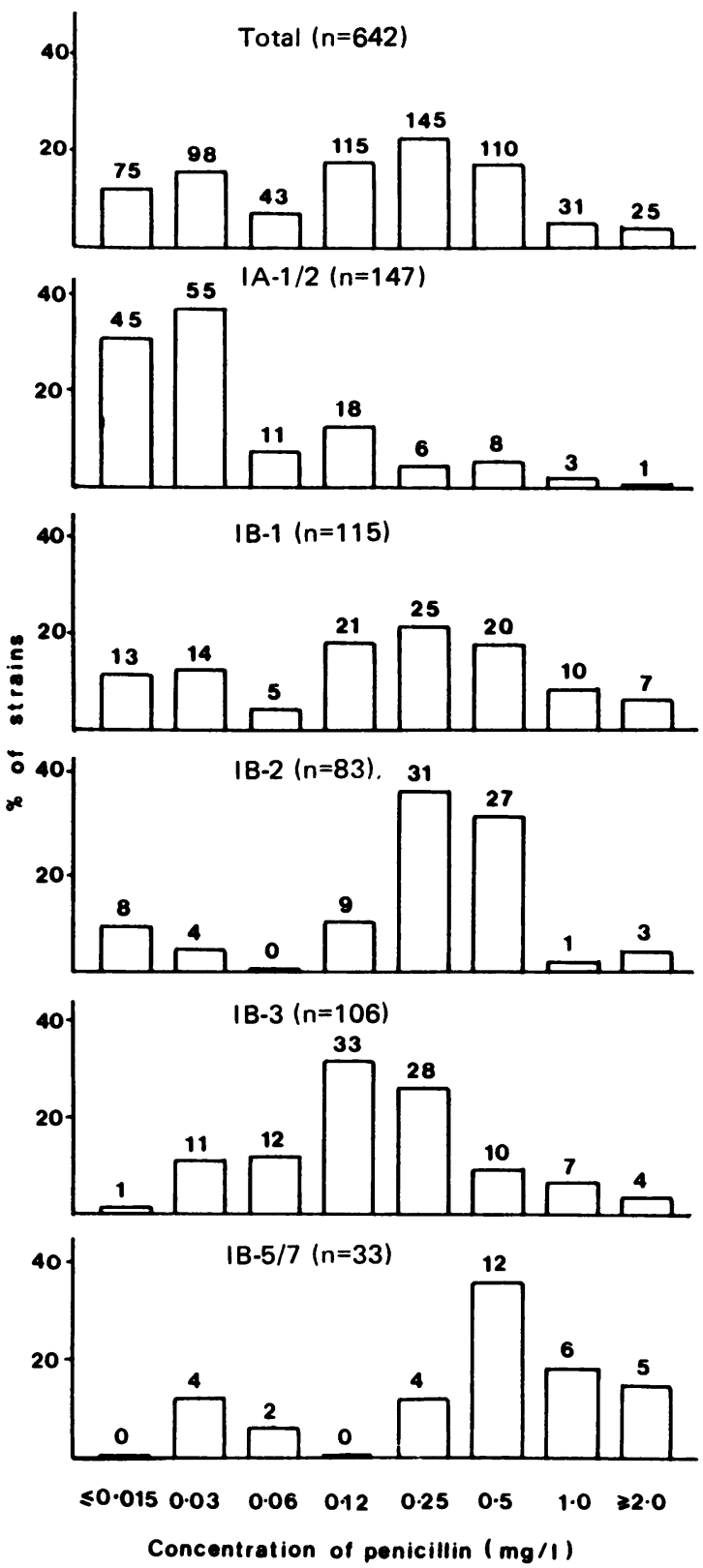

Fig 1 Distribution of susceptibility to penicillin for serovars $I A-1 / 2, I B-1, I B-2, I B-3$, and $I B-5 / 7$ compared with that for the total population. No of strains inhibited by each concentration shown at top of each column.

$(37 / 275,14 \%)$ or cervical $(28 / 316,9 \%)$ strains were of serovar IB-2 and significantly $(\mathrm{p}<0.05)$ fewer rectal $(3 / 59,5 \%)$ than urethral $(46 / 275,17 \%)$ or cervical $(58 / 316,18 \%)$ strains were of serovar IB-3.

Strains of serovar IB-2 were isolated from sig- 

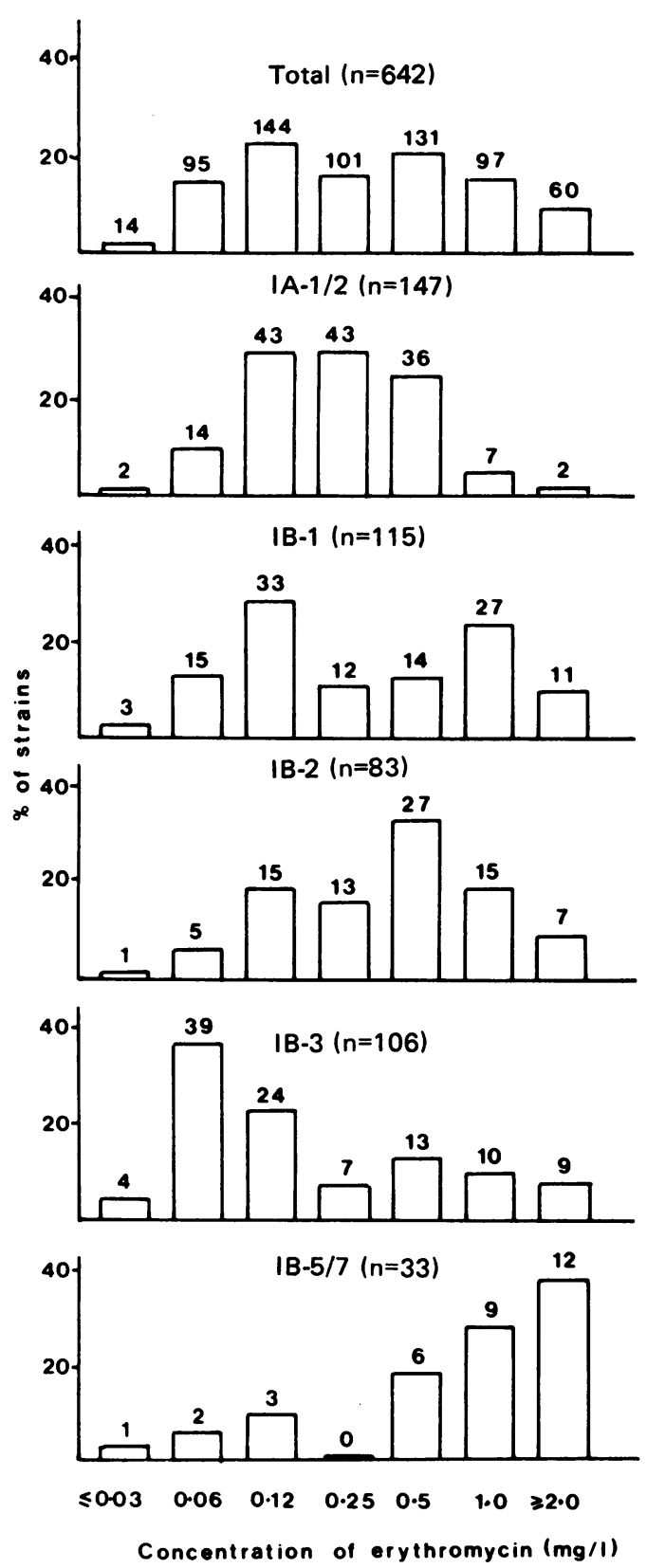

Fig 2 Distribution of susceptibility to erythromycin for serovars $I A-1 / 2, I B-1, I B-2, I B-3$, and IB-5/7 compared with that for the total population. No of strains inhibited by each concentration shown at top of each column.

nificantly more homosexual men (27/111) than heterosexual men $(28 / 223)$ or women $(28 / 316)$ $(p<0 \cdot 001)$. Most $(136 / 147)$ strains of serovar IA-1/2 were associated with heterosexually acquired infec-
Table 2 Distribution of predominant serovars by site of isolation from 650 patients

\begin{tabular}{llll}
\hline \multicolumn{5}{c}{ No $(\%)$ of isolates from } \\
\cline { 2 - 4 } Serovar & $\begin{array}{l}\text { Urethra }(\text { men }) \\
(n=275)\end{array}$ & $\begin{array}{l}\text { Rectum }(\text { men }) \\
(n=59)\end{array}$ & $\begin{array}{l}\text { Cervix } \\
(n=316)\end{array}$ \\
\hline IA-1/2 & $57(20 \cdot 7)$ & $4(6 \cdot 8)$ & $86(27 \cdot 2)$ \\
IB-1 & $52(18 \cdot 9)$ & $8(13 \cdot 6)$ & $55(17 \cdot 4)$ \\
IB-3 & $46(16 \cdot 7)$ & $3(5 \cdot 1)$ & $58(18 \cdot 4)$ \\
IB-2 & $37(13 \cdot 5)$ & $18(30 \cdot 5)$ & $28(8 \cdot 9)$ \\
IB-5/7 & $9(3 \cdot 3)$ & $3(5 \cdot 1)$ & $21(6 \cdot 6)$ \\
IB-8 & $8(2 \cdot 9)$ & 0 & $6(1 \cdot 9)$ \\
IB-31 & $3(1 \cdot 1)$ & 0 & $10(3 \cdot 2)$ \\
IB-16 & $5(1 \cdot 8)$ & $1(1 \cdot 7)$ & $6(1 \cdot 9)$ \\
IB-6 & $9(3 \cdot 3)$ & $2(3 \cdot 4)$ & 0 \\
IA-6 & $8(2 \cdot 9)$ & 0 & $3(1 \cdot 0)$ \\
IA-4 & $8(2 \cdot 9)$ & $1(1 \cdot 7)$ & 1 \\
IA-10 & $1(0 \cdot 4)$ & $1(1 \cdot 7)$ & $6(1 \cdot 9)$ \\
IB-4 & $5(1 \cdot 8)$ & $2(3 \cdot 4)$ & $1(0 \cdot 3)$ \\
IB-26 & $2(0 \cdot 7)$ & $2(3 \cdot 4)$ & $3(1 \cdot 0)$ \\
Others & $25(9 \cdot 1)$ & $14(23 \cdot 7)$ & $32(10 \cdot 0)$ \\
\hline
\end{tabular}

tions ( $\mathrm{p}<0.001$ ), and these strains tended to be more common in cervical (86/147) than urethral (57/147) isolates $(p=0.08)$. Strains of serovar IB-5/7 failed to show any significant associations with either the site of isolation (table 2) or the sexual preference of the patient.

\section{Discussion}

This study aimed to investigate associations between serovar and other bacterial and host characteristics for the strains collected. Though we did not intend to undertake a full study of prevalence of strains from patients attending the Praed Street Clinic, the sampling method used (20 strains a month) did represent the total population well (Bindayna KM et al, unpublished observation).

The non-PPNG strains collected during this study showed considerable serological heterogeneity, representing 41 serovars. Five serovars predominated, however, four of which (IA-1/2, IB-1, IB-2, and IB-3) each represented more than $10 \%$ of the strains studied. It remains unclear whether these serovars represented single populations or whether the use of additional monoclonal antibodies would allow subtyping. Tam et al described more monoclonal antibodies than are included in the standard panel. ${ }^{12}$ Some of these might be used selectively to allow subdivision of the major serovars, and would therefore complement results obtained with the standard panel. In contrast, Bygdeman et al have incorporated more antibodies into their standard panel and use them for all gonococcal strains. ${ }^{13}$ In our experience this is confusing as it results in a large number of serovars and hence excessive discrimination (unpublished observations).

Most $(607 / 650,93 \%)$ of the strains tested belonged to six auxotypes, but the combination of auxotype 
with the serotype as described by Knapp et al, ${ }^{8}$ divided strains into many auxotype/serotype classes, each of which contained relatively few isolates. We think that, though auxotype/serotype classes may be of value in identifying possible sexual contacts and in monitoring treatment failure, the level of discrimination given is too great for most association studies. Individual auxotypes may also be further subdivided by examining the genetic basis of the nutritional defect. ${ }^{145}$ Copley identified two distinct genetic lesions, presumably affecting different steps in the same biosynthetic pathway, which gave identical proline requiring phenotypes in clinical isolates. ${ }^{15}$ For this reason, strains of a particular auxotype/serotype class may not all be identical. ${ }^{16}$

In accordance with our previous findings,' the total population showed a bimodal distribution of susceptibility to penicillin. For individual serovars this pattern was seen clearly for IB-1 but less so for IB-2 and IB-3. Strains of serovar IA-1/2, however, were significantly more sensitive to penicillin, and strains of serovar IB-5/7 were significantly more resistant. Most $(88 / 147,60 \%)$ strains of serovar IA-1/2 required arginine, hypoxanthine, and uracil $\left(\mathrm{AHU}^{-}\right)$for growth. Strains of this auxotype have been shown to be hypersensitive to penicillin. ${ }^{17}$ To our knowledge, this is the first report of greater resistance in strains of serovar IB-5/7, although decreased susceptibility to penicillin has been associated with strains reacting with one of the monoclonal antibodies (2G2) that help to define this serovar. ${ }^{18}$ Strains of serovars IB-5/7 and IB-2 were also less susceptible to spectinomycin than strains of the other predominant serovars. Given the narrow range of susceptibility to this antibiotic, however, such differences should be treated with caution.

This association between PI serotype and the degree of susceptibility to penicillin and spectinomycin, two hydrophilic antibiotics, may reflect the influence of PI in the mode of action of these and similar antimicrobial agents. Protein $I$ is a transmembrane porin and provides the main route of entry into the cell for hydrophilic compounds. ${ }^{192}$ The serovar of a strain is determined by the epitopes exposed on the surface of PI. $^{812}$ Each serovar therefore represents a different combination of such epitopes. These combinations may affect the conformation of PI, which may result in variations in the permeability of the porin. The possibility that PI serotype may affect permeability requires further investigation.

The prevalence of strains belonging to serogroups IA and IB has been reported as varying at different genital sites. Serogroup IA strains are associated with the cervix ${ }^{7}$ and with heterosexual infections, whereas strains isolated from the rectum and from homosexual men are predominantly of serogroup IB. ${ }^{21} 22$ These differences may be solely epidemiological phenomena and attributable to strains circulating in relatively closed populations. It has been postulated, however, that the differences may have a biological base. The rectum is a hydrophobic environment, and gonococci must overcome these adverse conditions if they are to survive at this site. Because of this selection, gonococci causing rectal infections therefore tend to be resistant to hydrophobic molecules. ${ }^{23}$ The $m t r$ mutation confers resistance to a variety of hydrophobic antibiotics and dyes such as erythromycin, fusidic acid, crystal violet, and triton X-100. ${ }^{4}$ Strains carrying this mutation have an advantage for survival in the rectum and are more common in isolates from homosexual men than from heterosexual men. ${ }^{23}$

In our population we examined the association between susceptibility to erythromycin (as a marker for resistance to hydrophobic molecules), site of isolation, and the sexual preference of the patient. Several distinct patterns were found. Strains of serovar IB-1 showed a bimodal distribution in their susceptibility to erythromycin and were isolated equally from the three anatomical sites. This large group of strains $(115 / 650)$ may have consisted of two distinct subpopulations, one of which was susceptible and one resistant to hydrophobic molecules. Strains of serovar IB-2 were more resistant to erythromycin and were more prevalent in rectal isolates and isolates from men with homosexually acquired infections. This association between strains of serovar IB-2 and homosexually acquired infection has also been recognised by other workers. ${ }^{24}$ Conversely, strains of serovar IB-3 were rarely isolated from rectal and homosexual infections and were more susceptible to erythromycin.

These associations do appear to support the hypothesis that resistance to hydrophobic molecules is necessary for gonococcal survival in the rectum. ${ }^{23}$ Some serovars that were moderately resistant to erythromycin, however, notably IA-1/2, were rarely isolated from the rectum and were more commonly found in the cervix. Clearly there must be important factors other than simply resistance to hydrophobic molecules. The importance of epidemiological pressure related to the patterns of sexual behaviour must not be overlooked.

Serological classification is based on variations in the major outer membrane protein (MOMP), PI. This is a porin with no role in gonococcal attachment, ${ }^{25}$ and is therefore unlikely to be directly implicated in tissue tropism. The serovar classification may of course be a marker for other more relevant biological characteristics. Most serovar IA-1/2 strains isolated were of the $\mathrm{AHU}^{-}$auxotype. Strains of this auxotype tend to form transparent colonies, ${ }^{26}$ a characteristic associated with infections in women, particularly after menstruation. ${ }^{27} 28$ Transparency is related to the nature of 
another family of MOMPs, P2, which is associated with gonococcal adherence to epithelial cells ${ }^{2930}$ and therefore could be linked to site selection.

Serological typing of $N$ gonorrhoeae is proving to be a powerful tool not only for epidemiological work, but also, as shown here, for studying the biology of resistance to antimicrobials, tropism related to site of infection, and survival.

We thank Syva, Palo Alto, USA, for the kind gift of the monoclonal antibodies.

This study was supported by Upjohn International.

\section{References}

1 Reyn A, Korner B, Bentzon MW. Effects of penicillin, streptomycin and tetracycline on Neisseria gonorrhoeae isolated in 1944 and 1957. British Journal of Venereal Diseases 1958; 34:227-39.

2 Faruki H, Kohmescher RN, McKinney WP, Sparling PF. A community-based outbreak of infection with penicillin-resistant Neisseria gonorrhoeae not producing penicillinase (chromosomally-mediated resistance). $N$ Engl J Med 1985; 313:607-11.

3 Brown S, Warnnissorn T, Biddle J, Panikabutra K, Traisupa A. Antimicrobial resistance of Neisseria gonorrhoeae in Bangkok: is single drug treatment passé? Lancet 1982;ii:1366-8.

4 Cannon JG, Sparling PF. The genetics of the gonococcus. Annu Rev Microbiol 1984;38:111-33.

5 Rice RJ, Biddle JW, JeanLouis YA, DeWitt WE, Blount JH, Morse SA. Chromosomally-mediated resistance in Neisseria gonorrhoeae in the United States; results of surveillance and reporting, 1983-1984. J Infect Dis 1986;153:340-5.

6 Dowsett EG. Penicillin-resistant gonococci. Lancet 1980;ii:202.

7 Ison CA, Gedney J, Easmon CSF. Chromosumal resistance of gonococci to antibiotics. Genitourin Med 1987;63:239-43.

8 Knapp JS, Tam MR, Nowinski RC, Holmes KK, Sandstrom EG. Serological classification of Neisseria gonorrhoeae with use of monoclonal antibodies to gonococcal outer membrane protein 1. J Infect Dis 1984;150:44-8.

9 Knapp JS, Holmes KK, Bonin P, Hook EW III. Epidemiology of gonorrhoea: distribution and temporal changes in auxotype/ serovar class of Neisseria gonorrhoeae. Sex Transm Dis 1987;14:26-32.

10 Rice RJ, Hook EW III, Holmes KK, Knapp JS. Evaluation of sampling methods for surveillance of Neisseria gonorrhoeae. In Poolman J, ed. Gonococci and meningococci. Dordrecht: Kluwer Academic, 1988:167-73.

11 Copley CG, Egglestone SI. Auxotyping of Neisseria gonorrhoeae isolated in the United Kingdom. J Med Microbiol 1983;16: 295-302.

12 Tam MR, Buchanan TM, Sandstrom EG, et al. Serological classification of Neisseria gonorrhoeae with monoclonal antibodies. Infect Immun 1982;36:1042-53.

13 Bygdeman SM, Gillenius EC, Sandstrom EG. Comparison of two sets of monoclonal antibodies for the serological classification of Neisseria gonorrhoeae. In: Schoolnik GK, Brooks GF, Falkow S, eds. The pathogenic neisseriae. Washington DC: American Society for Microbiology, 1985:31-6.
14 Catlin BW. Genetic transformation of biosynthetically defective Neisseria gonorrhoeae clinical isolates. J Bacteriol 1974; 120:203-9.

15 Copley CG. Neisseria gonorrhoeae: subdivision of auxogroups by genetic transformation. Genitourin Med 1987;63:153-6.

16 Morse SA, Johnson SR, Biddle JW, Roberts MC. High-level tetracycline resistance in Neisseria gonorrhoeae is result of acquisition of streptococcal tetM determinant. Antimicrob Agents Chemother 1986;30:664-70.

17 Knapp JS, Thornsberry C, Schoolnik GK, Wiesner PJ, Holmes KK, the Cooperative Study Group. Phenotypic and epidemiologic correlates of auxotype in Neisseria gonorrhoeae. J Infect Dis 1978;138:160-5.

18 Bygdeman S. Polyclonal and monoclonal antibodies applied to the epidemiology of gonococcal infection. In: Young $\mathrm{H}$, McMillan A, eds. Immunological diagnosis of sexually transmitted diseases. New York: Marcel Dekker, 1987:117-65.

19 Douglas JT, Lee MD, Nikaido H. Protein 1 of Neisseria gonorrhoeae outer membrane is a porin. FEMS Microbiology Letters 1981;12:305-9.

20 Lynch EC, Blake MS, Gotschlich EC, Mauro A. Studies of porins: spontaneously transferred from whole cells and reconstituted from purified proteins of Neisseria gonorrhoeae and Neisseria meningitidis. Biophys J 1984;45:104-7.

21 Bygdeman S. Gonorrhoea in men with homosexual contacts: serogroups of isolated gonococcal strains related to antibiotic susceptibility, site of infection, and symptoms. British Journal of Venereal Diseases 1981;57:320-4.

22 Reid KG, Young H. Serogrouping Neisseria gonorrhoeae: correlation of coagglutination serogroup WII with homosexually acquired infection. British Journal of Venereal Diseases 1984;60:302-5.

23 Morse SA, Lysko PG, McFarland L, et al. Gonococcal strains from homosexual men have outer membranes with reduced permeability to hydrophobic molecules. Infect Immun 1982; 37:432-8.

24 Kohl PK, Henze I, Petzoldt D. Epidemiology of Neisseria gonorrhoeae: association of the prototrophic auxotype/1B-2 serovar of Neisseria gonorrhoeae with isolates from homo- and bisexual patients. Nouvelles Dermatologiques 1988:7 suppl 2:262.

25 Blake MS, Gotschlich EC. Gonococcal membrane proteins: speculation on their role in pathogenesis. Prog Allergy 1983; 33:298-313.

26 Tight $\mathbf{R}$, Jones $\mathbf{R}$. Colony opacity of gonococci from patients with disseminated gonococcal infection (DGI) and asymptomatic urethritis. In: Abstracts of the National Meeting. Washington DC: American Society for Microbiology, 1980;abstract B91.

27 James JF, Swanson J. Studies on gonococcus infection. XIII. Occurrence of colour/opacity variants in clinical cultures. Infect Immun 1978;19:332-40.

28 James JF, Swanson J. Colour/opacity variants of Neisseria gonorrhoeae and their relationship to the menstrual cycle. In: Brooks GF, Gotschlich EC, Holmes KK, Sawyer WD, Young FE, eds. Immunobiology of Neisseria gonorrhoeae. Washington DC: American Society for Microbiology, 1978:338-43.

29 Lambden PR, Heckels JE, James LT, Watt PJ. Variations in surface protein composition associated with virulence properties in opacity types of Neisseria gonorrhoeae. J Gen Microbiol 1979;114:305-12.

30 Virji M, Everson JS. Comparative virulence of opacity variants of Neisseria gonorrhoeae strain P9. Infect Immun 1981;31:965-70. 